FINAL REPORT

FOR THE PROGRAM

\title{
DIFFUSION OF OXYGEN IN LIQUID-METAL SYSTEMS
}

Contract DE-AT 03-76ER70037

Submitted to

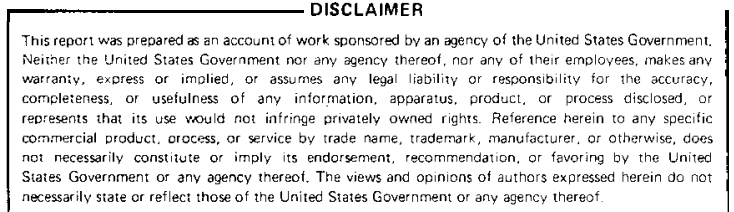

DEPARTMENT OF ENERGY

WASHINGTON, D.C. 20545

by the

BOARD OF TRUSTEES OF STANEORD UNIVERSITY

STANFORD, CALIFORNIA

January 1983

Principal Investigator:

David A. Stevenson

Department of Materials

Science and Engineering 


\section{DISCLAIMER}

This report was prepared as an account of work sponsored by an agency of the United States Government. Neither the United States Government nor any agency Thereof, nor any of their employees, makes any warranty, express or implied, or assumes any legal liability or responsibility for the accuracy, completeness, or usefulness of any information, apparatus, product, or process disclosed, or represents that its use would not infringe privately owned rights. Reference herein to any specific commercial product, process, or service by trade name, trademark, manufacturer, or otherwise does not necessarily constitute or imply its endorsement, recommendation, or favoring by the United States Government or any agency thereof. The views and opinions of authors expressed herein do not necessarily state or reflect those of the United States Government or any agency thereof. 


\section{DISCLAIMER}

Portions of this document may be illegible in electronic image products. Images are produced from the best available original document. 


\section{ABSTRACT}

A research program is described on the topic of kinetic and thermodynamic measurements in liquid metal-oxygen systems. This study has utilized electrochemical cells with solid-oxide electrolytes in several different configurations. The principal properties that were studied include: activities of the components in binary metal-metal alloy systems; oxygen solubility and oxygen diffusivity in pure liquid metals and liquid-metal alloys; and the free energy of formation of pure metal oxides. The techniques of solid-state electrochemistry were developed and the limitations of the techniques were studied. There were sufficient problems with the zirconia electrolytes to motivate a separate study on the degradation of zirconia electrolytes during their use. The electrolytic properties, as measured by complex impedance spectroscopy, was correlated with the microstructure, as evaluated by $x$-ray, optical microscopy, scanning electron microscopy, and transmission electron microscopy. Mechanisms for electrolyte degradation were proposed. 


\section{Introduction}

This research program has developed solid state electrochemical techniques for investigating high temperature thermodynamic and kinetic properties of liquid metal-oxygen and liquid metal-metal alloy systems. These systems are of interest for several reasons: oxygen is a significant solute in most liquid metals (oxygen is commonly present in liquid metals, either present initially or arising from sources in the vapor or from refractory containers); oxygen exerts an important influence on mechanical, chemical and electrical properties of metals and semiconductors; and oxygen exerts a significant influence on liquid metal corrosion, a form of corrosion occurring in liquid metal heat exchanger systems. In addition, there is interest in the use of solid electrolytes as oxygen sensors and oxygen pumps in many practical applications, especially for monitoring and controlling combustion processes to increase fuel efficiency and improve emissions. This research program may be divided into three major phases, which correspond roughly to three separate Ph.D. topics: the development of basic solid state electrochemical techniques and their application to diffusion and solubility studies in the Ga-In-O and the Sb-Bi-O systems; extension of these techniques to include the influence of solute additions of $\mathrm{Sn}, \mathrm{Pb}, \mathrm{Cu}, \mathrm{Ag}$ and $T i$ on the In-O system; and a detailed study of the changes of electrolytic conductance and the structure of the electrolyte during the use of zirconia electrolyte for these 
and other applications. This work has contributed to our fundamental knowledge of metal-metal oxide and liquid metal oxygen systems as well as furthering the technology of oxide electrolyte oxide sensors. This final report will summarize these three phases of the research in sections II, III, and IV. Section $V$ provides a listing of the journal articles that have appeared in the literature as a result of this research program. Further details of this study are given in these papers and in three $\mathrm{Ph} . \mathrm{D}$. theses.

II. Electrochemical Studies of the Ga-In-O and the Bi-Sb-O

\section{Systems}

The first phase of this program concerned the development of solid state electrochemical methods and their application to thermodynamic and kinetic investigations of the liquidmetal-oxygen systems: Ga-In and Sb-Bi alloy systems; Ga-O; In-O; Ga-In-O; Sb-O; $\mathrm{Bi}-0$; and $\mathrm{Sb}-\mathrm{Bi}-\mathrm{O}$. Because of the relatively low decomposition oxygen pressure of the corresponding oxides, these systems presented challenging experimental problems not encountered in earlier electrochemical studies. Yttria-doped thoria (YDT) and yttria stabilized zirconia (YSZ) were used as electrolytes in the Ga-O, In-O and Ga-In-O systems, whereas YSZ and calcia stabilized zirconia (CSZ) were used in Sb-O, Bi-O, Sb-Bi and $\mathrm{Sb}-\mathrm{Bi}-\mathrm{O}$ systems because of the electrolytic domain range requirements in the first three systems. 
Four different types of measurements were made. The first type of measurement was the experimental determination of activity in binary liquid alloy using a potentiometric technique. The activities of antimony in antimony-bismuth alloys were determined as a function of composition and temperature and the activities of $\mathrm{Bi}$ were calculated from the Gibbs-Duhem equation for the temperature ranges between 800 and $950^{\circ} \mathrm{C}$. This system showed small deviations from ideality and could be treated with a regular solution model.

The second type of measurement was the determination of the Gibbs energies of formation of the metal oxides in the Sb-O and Bi-O systems. Reliable information on the Gibbs energies of formation of the most stable oxides in these systems were needed in order to carry out oxygen diffusivity measurements. The Gibbs energies of formation of $\mathrm{Sb}_{2} \mathrm{O}_{3}$ were measured from 800 to $950^{\circ} \mathrm{C}$ using an electrode consisting of a $\mathrm{Sb}(1) / \mathrm{Sb}_{2} \mathrm{O}_{3}(1)$ two phase mixture. Two methods of preparing this mixture were used: in-situ synthesis of $\mathrm{Sb}_{2} \mathrm{O}_{3}$ by electrochemical titration of oxygen; and a straight mixing of the two phases. The results for these two procedures were in good agreement with each other and a least squares analysis of the data from the present investigation resulted in the following analytical representation for the Gibbs energy of formation of $\mathrm{Sb}_{2} \mathrm{O}_{3}(1)$ :

$$
\begin{aligned}
& \Delta G_{f}^{\circ}\left(S_{2} O_{3}, T\right) \quad\left(\mathrm{kcal} \text { mole } e^{-1}\right) \\
& =[(-109.1+0.020 \mathrm{~T}) \pm 0.4], 1073 \leq \mathrm{T} \leq 1223^{\circ} \mathrm{K} .
\end{aligned}
$$


These results are significantly lower than those in the literature which had been estimated by extrapolation of low temperature calorimetric data. The Gibbs energies of formation of $\mathrm{Bi}_{2} \mathrm{O}_{3}$ were also measured over the same temperature interval. A least squares analysis of the values of the Gibbs energy of formation of $\mathrm{Bi}_{2} \mathrm{O}_{3}$ resulted in the following analytical representation:

$$
\begin{aligned}
& \Delta \mathrm{G}_{\mathrm{f}}^{\circ}\left(\mathrm{Bi}_{2} \mathrm{O}_{3}, \mathrm{~T}\right)\left(\mathrm{kcal} \mathrm{mole}^{-1}\right) \\
& =[(-99.3+0.031 \mathrm{~T}) \pm 0.4], 1073 \leq \mathrm{T} \leq 1223^{\circ} \mathrm{K}
\end{aligned}
$$

The third type of measurement involved the use of coulometric-potentiometric titration technique to measure the solubilities of oxygen in liquid metals. This type of measurement was applied to gallium at $950^{\circ} \mathrm{C}$, liquid indium from 850 to $950^{\circ} \mathrm{C}$, and liquid bismuth and antimony between 800 and $950^{\circ} \mathrm{C}$. Activity was determined as a function of composition from the analyses of coulometric titration curves. All these metal-oxygen systems followed Henrian behavior up to the maximum oxygen solubility.

The diffusion coefficient of oxygen was measured in elemental liquid metals and in liquid metallic alloys in the temperature region between 750 and $950^{\circ} \mathrm{C}$ using a potentiostatic technique. The systems studied were: Ga, In, Sb, Bi, Ga-In and $\mathrm{Sb}-\mathrm{Bi}$. The large differences in oxygen diffusivity between liquid gallium and indium previously reported in the literature were confirmed and $D(O$ in $B i)$ was larger than $D(O$ in $S b)(\approx 2$ times), for the temperatures of interest. In Ga-In alloy 
systems, the major change in the diffusion coefficient occurs in the first few atomic percent change from the respective pure components, whereas diffusion studies in Sb-Bi alloy systems showed gradual changes in $D(0)$.

III. Influence of Solutes on the Thermodynamics and Diffusivity of Oxygen in Liquid Indium

The influence of small additions of the solutes tin, lead, copper, silver and titanium on the diffusivity, the solubility, the activity and the activity coefficient of oxygen in liquid indium was studied for the temperature range 750 to $950^{\circ} \mathrm{C}$ using solid state electrochemical techniques. Sharp increases in oxygen diffusivity and decreases in oxygen solubility were observed in all cases when these solutes were added to indium. There were relatively small changes in oxygen diffusivity with solute concentration observed for higher solute concentrations. Oxygen showed Henrian behavior up to the maximum oxygen solubility for all the temperatures and solute concentrations. The results indicated that the addition of a less reactive metal to a more reactive metal increases the oxygen diffusivity and decreases the oxygen solubility in the more reactive metal. A solubility-diffusivity correlation proved to be valid for all the indium-solute-oxygen systems. The thermodynamics of liquid binaries of indium-solutes were also studied using a solid oxide electrochemical method up to 10 atomic percent of these solutes. 
Reexamination of presently available data for eight different liquid metals showed that a solubility-diffusivity correlation is not universally applicable for comparing different pure liquid metal-oxygen systems. There is evidence that a more reactive metal will have a lower maximum solubility, a lower activity coefficient, and a higher solubility at a given oxygen activity, in contrast to a less reactive metal. On the basis of this observation, an empirical relationship was developed to estimate maximum oxygen solubilities in various liquid metals at $950^{\circ} \mathrm{C}$, from the saturation activity of oxygen in the liquid metal at that temperature.

It was observed that the conductivity of the electrolyte tubes decreased with use at high temperatures and in contact with liquid metals and that this decrease caused differences in the values of oxygen diffusivity measured at different times. Correction factors were developed for the diffusivity values using both calcia-stabilized zirconia and yttria-stabilized zirconia electrolyte tubes. Conductivities and the rate of decrease in conductivity of both electrolytes were measured by in situ DC conductivity measurements. To avoid the above mentioned sources of experimental error, a potentiostatic titration method was used to remeasure oxygen diffusivities and solubilities in pure liquid indium, gallium, antimony and bismuth. 
IV. Electrical and Microstructural Characterization of Stabilized Zirconia Solid Electrolytes

As mentioned in Section III, we have observed a decrease in conductivity of partially stabilized zirconia-yttria electrolytes (PSZ). The PSZ electrolytes are attractive because of their good electrolytic properties combined with good mechanical and thermal shock resistance. The present study was motivated by experimental problems encountered in electrochemical studies that may be attributed to the electrolyte; the performance of commercially available $\mathrm{Y}_{2} \mathrm{O}_{3}$-PSZ electrolytes has not been consistent. This phase of the research program concerned the influence of the preparation and thermal history on the properties of yttria and scandia stabilized zirconia (YSZ and SSZ) electrolyte samples. The various components of the conductivity were determined over a wide variety of electrolyte samples and ambient conditions and the conductivity was related to the microstructure of the electrolyte. The approach of the study consisted of complex admittance analysis of as-received (AR) anci annealed samples under a variety of conditions along with parallel microstructural observations of these samples using scanning and transmission electron microscopy.

The ac electrical conductivity was investigated for different yttria-stabilized zirconia (YSZ) solid electrolytes $\left(\mathrm{zrO}_{2}+\mathrm{X}\right.$ mole $\mathrm{Y}_{2} \mathrm{O}_{3}$ with $\mathrm{X}=0.045,0.07,0.08,0.1$ for polycrystalline samples and $x=0.094$ for single crystals) 
using porous Pt-paste electrodes and for temperature in the range of $400-1000^{\circ} \mathrm{C}$ and for ambient atmosphere of air and $\mathrm{PO}_{2}=10^{-20} \mathrm{~atm}$. The complex admittance of these specimens was determined over a wide frequency range, from $2 \mathrm{HZ}$ to $400 \mathrm{kHz}$. The frequency independent bulk conductivity is separated from grain boundary effects and from electrode-electrolyte interface contributions through the analysis of the complex admittance plots. The conductivities and related activation energies for YSZ systems were determined as a function of $\mathrm{Y}_{2} \mathrm{O}_{3}$ content and 8 mole $8 \mathrm{Y}_{2} \mathrm{O}_{3}-\mathrm{YSZ}$ (fully stabilized zirconia; FSZ) was found to have maximum conductivity and minimum activation energy for ionic conduction in the $600^{\circ}-1000^{\circ} \mathrm{C}$ range. The analysis of complex admittance plots specifies an electrolyte polarization (shown with parallel R-C network), corresponding to a partial blocking of oxygen ions at the electrolyte grain boundaries by a second phase. The influence of impurities, grain size, stabilizer content, on the different components of the conductivity were also investigated.

The change of conductivity on annealing (aging) of YSZ electrolytes was investigated for the annealing temperatures of $800^{\circ}, 900^{\circ}, 1000^{\circ} \mathrm{C}$. The aging in partially stabilized zirconia with 4.5 mole $8 \mathrm{Y}_{2} \mathrm{O}_{3} \quad\left(\mathrm{Y}_{2} \mathrm{O}_{3}-\mathrm{PSZ}\right)$ was attributed to the following three microstructural developments: (1) segregation of an yttria-rich layer at the grain boundaries and triple points; (2) precipitation of pure tetragonal $\mathrm{ZrO}_{2}$ from the 
cubic phase at the temperatures $\leq 1000^{\circ} \mathrm{C}$ (as a result of the above $\mathrm{Y}_{2} \mathrm{O}_{3}$ grain boundary segregation) and retention of this metastable phase along with stabilized cubic fluorite phase upon cooling to $\mathrm{T}<600^{\circ} \mathrm{C}$; and (3) formation of the ordered microdomains, with the composition of $\mathrm{Zr}_{3} \mathrm{Y}_{4} \mathrm{O}_{12}$, within the disordered cubic phase.

The influence of grain size, impurity content, stabilizer composition, and surrounding atmosphere on the aging kinetics of YSZ electrolyte was investigated. Slower aging rates are found in PSZ with larger grain size whereas opposite trends were observed in FSZ. The decreased aging effects in polycrystalline FSZ's compared to single crystals with identical $\mathrm{Y}_{2} \mathrm{O}_{3}$ content is attributed to the impeding of the ordered phase by the grain boundaries. The electrolyte $\mathrm{SC}_{2} \mathrm{O}_{3}-\mathrm{FSZ}$ (SSZ), which initially has $\approx 5-10$ times the conductivity of $\mathrm{Y}_{2} \mathrm{O}_{3}$-FSz with identical stabilizer content at $800^{\circ} \mathrm{C}$, was found to age much faster than $\mathrm{Y}_{2} \mathrm{O}_{3}-\mathrm{FSZ}$. The aging behavior of SSZ was explained in terms of formation of a rhombohedral (B) phase with the composition of $S_{2} \mathrm{Zr}_{7} \mathrm{O}_{17}$. The aging of $\mathrm{Y}_{2} \mathrm{O}_{3}$-PSZ (o(t) vs. $t$ ) could be characterized by a diffusion process $(\sigma(t) \propto \sqrt{E})$ while for $\mathrm{Y}_{2} \mathrm{O}_{3}-\mathrm{FSZ}$ and $\mathrm{Sc}_{2} \mathrm{O}_{3}-\mathrm{FSZ}$, the time dependence of conductivity is explained by an order-disorder transition ( $\sigma(t)$ a $\left.\exp \left(-\mathbb{K}^{\prime} t\right)\right)$. Supporting evidence for the observed aging behavior in both $\mathrm{Y}_{2} \mathrm{O}_{3}-\mathrm{PSZ}$ and $\mathrm{Sc}_{2} \mathrm{O}_{3}-\mathrm{FSZ}$ (SSZ) was obtained by the microstructural studies. 
The microstructural characterization of these materials was obtained from scanning and transmission electron microscopy (SEM and TEM), utilizing energy dispersive $X$-ray spectroscopy (EDS). A typical two-phase mcrostructure is observed by TEM in both unaged and aged (two weeks in air at $1000^{\circ} \mathrm{C}$ ) PSZ specimens. The major differences between the two samples was the presence of large $(1-2 \mu \mathrm{m})$ intragranular tetragonal phase and diffuse scattered intensities in the aged samples. The presence of an yttria-rich glassy phase at the intergrains and triple points, as evidenced by EDS and selected area diffraction, suggests destabilization by the rejection of yttria from the matrix grains to the glassy yttria-rich grain boundary phase and simultaneous formation of intragranular tetragonal phase. The formation of this intragranular tetragonal phase is believed to be responsible for the sharp drop in conductivity of PSZ in the first 80-100 hours of aging at $1000^{\circ} \mathrm{C}$ in air.

The use of ac impedance spectroscopy in electrochemical measurement of oxygen diffusivity and solubility in solid and liquid metals and alloys was also demonstrated. The product of chemical diffusion coefficient and solubility of diffusing species (oxygen atoms) can be obtained for both solid or liquid metals from the appropriate boundary value solution of Fick's second law technique was examined for $\mathrm{Pt}(\approx \mathrm{l} \mu \mathrm{m}$ thick $)$ and $\mathrm{Ag}(\approx I$ $\mu \mathrm{m}$ thick) electrodes on a single crystal YSZ $(9.4$ mole 8 $\mathrm{Y}_{2} \mathrm{O}_{3}$ ) electrolyte for the temperature range of $500^{\circ}-1000^{\circ} \mathrm{C}$ 
or $500^{\circ} \mathrm{C}-850^{\circ} \mathrm{C}$, respectively. The analysis of results for the two electrodes determined the possible rate controlling process for the electrode reactions. For Pt electrode, oxygen dissociation, adsorption, and diffusion along the triple lines is the rate controlling process whereas for the silver electrode, the rate limiting step is the diffusion of oxygen atoms through the electrode.

The change of ionic conductivity of $\mathrm{Y}_{2} \mathrm{O}_{3}-\mathrm{PSZ}$ upon annealing in $\mathrm{SO}_{2}$-rich atmosphere was investigated and the observed increase in electrical conductivity in this atmosphere was attributed to the generation of free electrons. Therefore, there is mixed conduction in $\mathrm{SO}_{2}-\mathrm{O}_{2}$ ambients $\left(\mathrm{P}_{2}=\right.$ 0.21 atm.), in contrast to air ambients in which only pure ionic conductivity is observed. The conductivity measurements were supported by measurements of the reversible cell EMF. In both experiments electronic transference numbers of $0.3-0.35$ at $1000^{\circ} \mathrm{C}$ were measured.

The nature of the blackening of 8 mole $8 \mathrm{Sc}_{2} \mathrm{O}_{3}-\mathrm{zrO}$, resulting from passing a current of 5 amperes through the material at $700^{\circ} \mathrm{C}$ and $\mathrm{P}_{2}<10^{-7}$ atm., was investigated by TEM. It was found that a polycrystalline phase with small grain size $(\approx 100 \AA-200 \AA)$ is formed mainly at the grain boundaries and triple points. The lattice parameters of this phase were close to those of the original cubic fluorite structure. By electron diffraction pattern and EDS analysis, it was found that this phase does not correspond to any metallic zirconium phase, as has been previously postulated. 
v. Publications

Several noteworthy results of this research have been published in the open literature and are listed below. These articles provide specific detailed information on the topics specified by the respective titles.

A. Papers published:

1. "Oxygen Diffusion in the Ga-In-O System," High Temperature Science, 9, 165-187 (1977), (S.K. Hahn and D. A. Stevenson).

2. "Thermodynamic Investigation of Antimony + Oxygen and Bismuth + Oxygen Using Solid State Electrochemical Techniques," J. Chem. Thermodynamics 11, 627-637 (1979) (S. K. Hahn and D. A. Stevenson).

3. "Use of Solid Oxide Electrolytes for the Study of Oxygen Solubility and Diffusivity in Liquid Metals," P. Vashishta, J.N. Mundy and G.K. Shenoy, eds., Fast Ion Transport in Solids Electrodes and Electrolytes pp. 117-120 (1979) (D.A. Stevenson, B. Heshmatpour and F.K. Moghadam).

4. "Experimental Problems in the Use of Solid Oxide Electrolytes," J. Applied Electrochem. 11, 433-442. (1981) (B. Heshmatpour and D. A. Stevenson).

5. "Characterization of Yttria-Stabilized Zirconia Oxygen Solid Electrolytes," Advances in Ceramics Vol. 3, Science and Technology of Zirconia, A.H. Heur and L.W. Hobbs eds., pgs. 364-379 (1981) (F.K. Moghadam, T. Yamashita and D.A. Stevenson).

6. "The Influence of Solute Additions of $T$ in, Lead and Titanium on the Kinetics and Thermodyramics of the Liquid In-O System," Journal of Less Common Metals, 81, pgs. 329-340 (1981). (B. Heshmatpour and D.A. Stevenson).

7. "An Electrochemical Study of the Solubility and Diffusivity of Oxygen in the Respective Liquid Metals Indium, Gallium, Antimony and Bismuth," J. Electroanal. Chem. 130 pgs. 47-55 (1981). (B. Heshmatpour and

D.A. stevenson).

8. "The Influence of Solute Additions of Copper and Silver on the Diffusivity and Thermodynamic Properties of Oxygen in Liquid Indium," J. Electrochem. Soc. 129, 430-436 (I982)

(B. Heshmatpour and D.A. Stevenson).

9. "Correlations for Thermodynamic and Kinetic Properties of Gas Solutes in Liquid Metal Solvents, "High Temperature Science 15, pgs. 55-57 (1982). (B. Heshmatpour, N.A.D. Parlee and D.A. Stevenson). 
10. "Influence of Annealing on the Electrical Conductivity of Polycrystalline $\mathrm{ZrO}_{2}+8 \mathrm{~W} \& \quad \mathrm{Y}_{2} \mathrm{O}_{3}$, " Journal of the American Ceramic Society, 65, 213-215 (1982)

(F.K. Moghadam and D.A. Stevenson).

11. "The Influence of Solutes on Kinetics and Thermodynamics of Liquid Indium-Oxygen Systems", Metallurgical Transactons B 13B, 53 (1982) (B. Heshmatpour and D.A. Stevenson).

B. Papers Accepted for Publication

1. "TEM Studies of Annealed $\mathrm{ZrO}_{2}+8$ mole $8 \mathrm{Sc}_{2} \mathrm{O}_{3}$," $\mathrm{J}$. American Ceramic Society. Accepted for publication F.K. Moghadam, T. Yamashita, R. Sinclair and D.A. Stevenson

2. "Characterization of the Current-Blackening Phenomena in Scandia Stabilized Zirconia Using Transmission Electron Microscopy," J. Materials Science, Accepted for publication, F.K. Moghadam, T. Yamashita and D.A. Stevenson

3. "Influence of $\mathrm{SO}_{2}$ on the Electrolytic Domain of Yttria Stabilized Zirconia," J. Applied Electrochemistry Acepted for publication, F.K. Moghadam and D.A. Stevenson

C. Paper in Preparation

1. "Application of Impedance Spectroscopy to the Diffusion of Oxygen in Platinum and Silver," F.K. Moghadam and D.A. Stevenson.

D. Ph.D. Dissertations

1. "Thermodynamic and Kinetic Investigations of Liquid Metal-Oxygen Systems Using Solid State Electrochemical Methods," S.K. Hahn.

2. "Kinetic and Thermodynamic Studies of Liquid Metal-oxygen Systems Using Solid State Electrochemical Techniques," B. Heshmatpour.

3. "Electrical and Microstructural Characterization of Stabilized Zirconia Solid Electrolytes," F.K. Moghadam. 